\title{
Resenha da nova edição brasileira da obra de Nicos Poulantzas, Poder político e classes sociais
}

\author{
Review of the new Brazilian edition of Nicos Poulantza's work: \\ Political Power and Social Classes
}

\section{Reseña de la nueva edición brasileña del trabajo de Nicos Poulantzas, Poder político y clases sociales}

\author{
Armando Boito Júnior ${ }^{1}$ \\ Universidade Estadual de Campinas, Professor titular \\ https://orcid.org/0000-0002-1826-7331
}

POULANTZAS, N. Poder político e classes sociais. 1. ed. Tradução: Maria Leonor F. R. Loureiro e Danilo Enrico Martuscelli. Campinas: Editora da Unicamp, 2019.

Recebida em 16 de setembro de 2019

Aceita em 14 de abril de 2020

A originalidade deste livro ${ }^{2}$ está presente já na construção do seu objeto de investigação: o nível jurídico-político do modo de produção capitalista e, particularmente, o tipo capitalista de Estado. 0 conceito ampliado de modo de produção, concebido não como sinônimo de economia, mas, sim, como conceito que contempla o todo complexo e articulado de distintas instâncias ou níveis da vida social, esse conceito ampliado é a referência de fundo que permitiu a Poulantzas construir o seu objeto. Foi por estar de posse de tal inovação conceitual, que ele pôde designar como objeto de investigação a instância ou o nível político do modo de produção capitalista. Até então, a produção da teoria política marxista tinha diante de si o obstáculo epistemológico representado pelo economicismo. É certo que esse obstáculo foi ultrapassado, na prática, pelas análises, contidas principalmente nas obras históricas de Marx, Engels, Lenin, Gramsci e outros clássicos. Ocorre que tal obstáculo seguia presente ainda, e produzindo efeitos teóricos negativos na teoria dos modos de produção. A ampliação desse conceito para além da economia, proposta pela escola althusseriana nos textos fundadores Por Marx e Para ler 0 Capital, permitiu a Poulantzas desalojar esse

Pós-doutor pela Fondation Nationale des Sciences Politiques, Paris; Doutor em Sociologia pela Universidade de São Paulo.

Uma versão do texto em tela consta no prefácio da obra resenhada, cuja publicação está prevista para o fim deste ano ou inícios de 2020. 
obstáculo de seu último reduto e descortinar um campo novo para a reflexão científica do marxismo. Tornaram-se, assim, possíveis as perguntas deste livro: Como o nível político apresenta-se no modo de produção capitalista, parte constitutiva e necessária que é desse modo de produção? Como o Estado capitalista permite a reprodução da economia capitalista? Como ele se distingue dos tipos de Estado característicos dos modos de produção précapitalistas? Essas são as perguntas fundamentais de Poder político e classes sociais.

As contribuições de Poulantzas neste livro são muitas, de tal modo que é difícil distinguir apenas algumas delas. Arriscaríamos, contudo, destacar duas que nos parecem fundamentais: a análise da instituição do Estado de tipo capitalista e a elaboração do conceito de bloco no poder.

0 livro mostra que o Estado de tipo capitalista, diferentemente do Estado escravista ou feudal, apresenta-se não como uma instituição de classe responsável pela organização da dominação de classe, mas, sim, como um Estado de "todo o povo". 0 Estado capitalista não aparece como aquilo que é, mas como algo que parece ser. Ele é o Estado de "todo o povo", entidade imaginária, mas muito real no nível da ideologia, criada por esse próprio Estado. As normas e os valores característicos dessa instituição, do seu direito e da organização do pessoal de Estado produzem efeitos ideológicos imprescindíveis para a reprodução das relações de produção capitalistas. Ou seja, na teoria política marxista, tal qual a desenvolve Nicos Poulantzas, as instituições são importantes e o são, inclusive, porque estão indissoluvelmente vinculadas à organização da economia e da sociedade.

As normas e os valores do Estado capitalista permitem a reprodução incessante da inserção relativamente pacífica dos trabalhadores no processo de produção/exploração capitalista, ao gerar a ilusão de um contrato entre partes livres e iguais. Produzem efeitos devastadores sobre a organização e a luta da classe operária, ao dissolvê-las num agregado de indivíduos singulares e ao contraporem, à sua potencial organização coletiva, a realidade do ilusório coletivo nacional, supostamente homogêneo e dotado de interesse geral comum. 0 segredo desses complexos efeitos ideológicos funcionais para a reprodução da economia capitalista reside no direito formalmente igualitário, como é o direito capitalista, e no burocratismo, também típico desse tipo de Estado e organizador da burocracia profissional de Estado. Esse direito e essa burocracia, formalmente aberta à participação de indivíduos egressos de toda e qualquer classe social, fazem a instituição Estado capitalista aparecer como se fosse uma instituição pública, e são a condição para a reprodução das relações de produção capitalistas. Essa novidade do livro, além de permitir uma análise mais profunda e rigorosa do 
funcionamento do Estado e das sociedades onde domina o modo de produção capitalista, tem consequências políticas de longo alcance no que respeita à teoria e à estratégia da transição socialista. Ela significa que não se pode transitar ao socialismo sem se suprimir o direito formalmente igualitário e a abertura formal dos postos de Estado a indivíduos provenientes de qualquer classe social. Na verdade, trata-se de uma fundamentação teórica da tese leninista segundo a qual a transição ao socialismo exige a destruição do aparelho de Estado burguês.

0 conceito de bloco no poder, por sua vez, trata, não da estrutura jurídico-política ou da instituição Estado capitalista, mas da prática das classes sociais na sociedade e junto ao Estado capitalista. Na análise daquela instituição, Poulantzas partiu, acima de tudo, de conceitos e teses contidos em 0 Capital, de Marx, e no livro Teoria geral do direito e marxismo, do jurista soviético Evguiéni Pachukanis, embora tenha modificado substancialmente pontos importantes dessa última obra. Já na análise do bloco no poder, o material principal são as análises históricas de Marx, Engels, Lenin e Gramsci. Ponto alto nessa elaboração é a leitura detalhada, crítica e criativa que Poulantzas realiza do clássico 18 Brumário de Louis Bonaparte, de Marx. Poulantzas sistematiza e desenvolve muito daquilo que se encontrava em estado prático em textos como esse e, ao fazê-lo, desenvolve e também retifica os textos clássicos. Os conceitos de fração burguesa, bloco no poder, hegemonia de fração e força social são alguns dos conceitos fundamentais que extraem, retificam, desenvolvem ou produzem nessa espécie de garimpo teórico. Analisando a presença política das classes populares, o autor desenvolve, também, conceitos inovadores como o de classe-apoio, imprescindível para a compreensão de fenômenos como o populismo e o bonapartismo, tão debatidos no Brasil.

A classe capitalista não é concebida, ao contrário do que ocorre em alguns autores marxistas, como um bloco homogêneo sem fissuras. Ela é analisada, regra geral, como um coletivo de classe, dotado de interesse político geral comum, mas subdividido em frações no que concerne a interesses econômicos de médio prazo. Atraídos por esses dois polos, o interesse de classe e o interesse de fração, os diferentes segmentos da classe capitalista podem realizar movimentos surpreendentes e até contraditórios. 0 bloco no poder é concebido, por sua vez, como a unidade, às vezes instável, dessas frações em conflito pelo controle da política econômica, social e externa do Estado. A fração que logra se firmar na posição de controle estabelece a sua hegemonia no interior do bloco no poder. A complexidade oriunda do entrecruzamento dos diversos sistemas de fracionamento da burguesia - porte do capital, origem do capital, inserção nas diferentes fases do processo de acumulação, etc. -, a composição e a correlação de forças entre as frações que integram o bloco, as relações variadas de tais frações com diferentes classes populares, todo esse conjunto de vetores cria um jogo político muito complexo que o dispositivo conceitual de Poulantzas permite deslindar. Estamos longe da oposição simples e simplificada entre a classe capitalista e a classe operária e é do que precisamos para a análise das conjunturas políticas. 
A obra de Poulantzas deixa entrever que a complexidade é ainda maior na medida em que as frações burguesas e demais forças sociais em presença não agem por si sós no processo político nem se encontram imunes à pressão popular. A burocracia de Estado tem um papel ativo na organização da hegemonia de fração, podendo, inclusive, impor sacrifícios à fração hegemônica na busca da manutenção da unidade e da estabilidade do bloco no poder. Poulantzas insiste muito, e essa é uma constante de suas reflexões teóricas, na crítica à concepção do Estado como instrumento passivo da classe capitalista ou de uma de suas frações. 0 Estado é, simultaneamente, arena e ator no conflito de classes. Dentro da correlação de forças dada, é papel da burocracia de Estado e dos políticos profissionais da burguesia definirem uma estratégia viável de desenvolvimento capitalista. Está aberta a possibilidade de conflitos entre o Estado e as frações presentes no bloco no poder, inclusive a fração hegemônica. Até porque, embora excluídas do bloco no poder, as classes populares, no modo de produção capitalista, fazem-se, diferentemente do que ocorria nos modos de produção pré-capitalistas, constantemente presentes no processo político, obrigando o Estado a procurar, por intermédio de concessões, aquilo que Poulantzas denomina "um equilibrio instável de compromisso" entre as forças em presença. Destoando, ainda, de importantes autores marxistas, Poulantzas toma em consideração a estrutura dos regimes políticos e dos sistemas partidários como componentes fundamentais do processo político. Aqui temos, também, outra de suas contribuições específicas para o desenvolvimento da teoria poĺtica marxista.

Característicos do método de trabalho teórico de Poulantzas são o estudo e a consideração das obras de teoria política produzidas fora do campo da teoria marxista. Poder político e classes sociais é um tratado cosmopolita, contempla as obras e contribuições publicadas nas principais línguas europeias e produzidas a partir de problemáticas as mais variadas: weberiana, elitista, funcionalista, estruturalista, institucionalista e outras. Assim procedendo, longe de introduzir uma novidade, tem, na verdade, o mérito de reatar com a prática teórica dos clássicos do marxismo que não deixavam de analisar e reaproveitar, quando necessário e possivel, obras inovadoras pertencentes a outros campos teóricos - recorde-se a apropriação/retificação de Morgan por Engels ou de Hobson por Lenin. Assim, nas notas de rodapé de Poder político e classes sociais, é oferecido ao leitor um retrato do estado da arte da ciência política acadêmica das décadas de 1940, 1950 e 1960. A leitura crítica da politologia em línguas inglesa, alemã, francesa e italiana efetuada por Poulantzas é um exemplo de trabalho escrupuloso, como deve ser o trabalho científico, seja para rejeitar conceitos e teses seja para reaproveitá-los, com sofisticadas retificações, na problemática marxista e na sua teoria política. 
0 trabalho de Nicos Poulantzas teve grande repercussão na Europa, nos Estados Unidos e na América Latina. Após um periodo de eclipse parcial essa obra volta a ser debatida e utilizada nessas regiões. No Brasil, um local destacado de estudo, debate e aplicação do dispositivo conceitual desenvolvido por Poulantzas tem sido a Unicamp. Diversos pesquisadores que trabalham ou trabalharam nessa Universidade ou que nela foram formados têm utilizado os conceitos desenvolvidos por Nicos Poulantzas na obra que ora apresentamos para analisar o Estado brasileiro e o processo politico nacional em diferentes periodos da nossa história. Outros pesquisadores em outras instituiç̃̃es e regiões do País também têm recorrido, e crescentemente, à obra Poder politico e classes sociais. 0 resultado é que temos, hoje, pesquisas e livros inspirados nos referidos conceitos de Poulantzas, analisando períodos e questões cruciais da história brasileira: o modo de produção escravista no periodo imperial, a revolução burguesa e a formação do Estado capitalista, as classes dominantes e a hegemonia na República Velha, a Revolução de 1930, as classes dominantes no período de 1930-1964, as crises poĺticas desse período, a ideologia nacional-desenvolvimentista, os movimentos sociais, o bloco no poder e o regime de ditadura miltar, bem como os conflitos de classe e as crises politicas na presente quadra da história brasileira na qual tem vigência o modelo capitalista neoliberal. Também inspiradas na obra de Poulantzas, já surgem análises das relações internacionais e da política externa do Estado brasileiro. Nesses trabalhos, os conceitos poulantzianos têm se revelado de grande valor para elucidar os processos politicos concretos e para esclarecer questões polêmicas da história politica do Brasil. A originalidade conceitual da obra de Poulantzas tem ensejado, como era de se esperar, teses originais sobre a política brasileira.

Poder político e classes sociais ocupa um lugar especial na história intelectual de Nicos Poulantzas. 0 livro, publicado em 1968, teve ampla repercussão e sucessivas edições num curto espaço de tempo. Nos anos subsequentes, Poulantzas publicou Fascismo e ditadura (1970), As classes sociais no capitalismo de hoje (1974), A crise das ditaduras Portugal, Grécia e Espanha, e, 10 anos após o livro que estamos apresentando, Poulantzas publicou, em 1978, Estado, poder e socialismo. Nesse último livro, ele abandonou o conceito de Estado da sua obra anterior, particularmente a tese segundo a qual o Estado capitalista é uma instituição dotada de normas e valores característicos que correspondem, objetiva e necessariamente, às exigências da reprodução das relações de produção capitalistas. 0 conceito de Estado desenvolvido em Poder político e classes sociais é, portanto, um dos 
conceitos de Estado presentes no conjunto da obra de Poulantzas, não o único. No plano teórico, a mudança indicada anteriormente significou, também, o abandono da tese segundo a qual o Estado capitalista é uma instituição material que impõe limites à atuação dos agentes que a ocupam. Em Estado, poder e socialismo, Poulantzas lançou a ideia de que o Estado seria a condensação da relação de forças entre as classes sociais em presença, dissolvendo, assim, a ideia de instituição limitadora e colocando no seu lugar uma instituição dotada, agora, de maleabilidade ilimitada e cuja natureza de classe alterar-se-ia - é o que se deve deduzir - em conformidade com as alterações ocorridas na referida relação.

Do ponto de vista político, e no que respeita particularmente à questão da transição socialista, Poulantzas se deslocou de uma posição teórica e política próxima do leninismo para uma posição próxima à do eurocomunismo. Poulantzas, embora de origem grega, era radicado na França. Na conjuntura de final da década de 1970, a esquerda francesa organizava e debatia a aliança do Partido Socialista com o Partido Comunista Francês em torno do Programa Comum e da candidatura de François Mitterrand à Presidência da República. Socialistas e comunistas sugeriam a viabilidade de um caminho constitucional, parlamentar e pacífico ao socialismo. Com o seu novo conceito de Estado, Poulantzas dava suporte a essa concepção de transição. Passou, então, a ser visto como um intelectual da ala esquerda do eurocomunismo - ala esquerda porque Poulantzas seguia insistindo na necessidade da mobilização operária e popular contra aqueles que sugeriam o confinamento da luta socialista na instituição parlamentar. Essa mudança de posição teórica e política teve, inclusive, repercussão negativa junto ao seu círculo de colaboradores e auxiliares no trabalho acadêmico, posto que alguns desses colaboradores se converteram em críticos do antigo mestre.

A mudança teórica e política empreendida por Nicos Poulantzas significou, na nossa avaliação, uma perda do rigor e da riqueza de sua contribuição para a teoria política marxista, mas este não é o lugar para aprofundarmos essa discussão, sem dúvida muito complexa. 0 que eu quis fazer foi indicar tal mudança ao leitor com o objetivo de informá-lo.

Observação: a tradução que ora publicamos é nova. Difere muito daquela publicada no Brasil pela Editora Martins Fontes em 1971 e que se encontra fora de catálogo. Aliás, na tradução de 1971 notamos vários problemas, inclusive a supressão de algumas páginas do texto original.

Endereço para correspondência: Cidade Universitária Zeferino Vaz, Barão Geraldo, Campinas, São Paulo, Brasil; armando.boito@gmail.com

Roteiro, Joaçaba, u. 45, p. 1-6, jan./ dez. 2020 | e23098 |E-ISSN 2177-6059 